\title{
Active Learning as a New Technology: Examining the Effects of Blogging in the Teaching of Writing
}

\author{
Nicole Roth Miller and Joseph C. Kush
}

\begin{abstract}
This study was conducted in an effort to determine what effects the implementation of blogging journaling activities into the teaching and learning of writing in the high school classroom would have on writing skills and student satisfaction. Three distinct journaling styles were compared: Group 1 consisted of participants who handwrote their journal entries each week for eleven weeks, Group 2 consisted of participants who word processed their journal entries each week, and Group 3 consisted of participants who blogged their journal entries each week. Overall, the findings indicated that the implementation of a blogging component into a standard writing course positively impacted the academic performance of participants; however, in spite of increased performance levels, the inclusion of blogging did not impact the level of enjoyment experienced by students any more than traditional instructional writing methods.
\end{abstract}

Index Terms-Active learning, blogging, high school, teaching writing

\section{INTRODUCTION}

Constructivist learning theory emphasizes that learners must be active creators of knowledge and further, that learning is a social process of negotiation and construction [1] With the advent of Web 2.0 technologies, writing and literacy instruction has paralleled this notion by emphasizing active and collaborative content creation [2]. There is growing evidence that the literacy practices that develop in different social or collaborative contexts and the values pertaining to these practices will differentially impact academic achievement [3]-[6].

Currently, blogs and blogging tools are typically implemented in an effort to efficiently share large quantities of knowledge, manage said knowledge and information, function as a customer service tool, facilitate interactive journalism and news reporting, assist in communication, allow for self-expression and self-marketing, encourage and facilitate learning, allocate space for campaigning and social reform, encourage community building, support experience tracking, and promote story telling (Siemens, 2002). Siemens admits that blogs are typically used as personal sounding boards, which suggests that they are being underutilized as an educational tool. The aforementioned list of blogging applications vividly portrays the flexibility of continually improving blogging technologies. For the purposes of this study, however, the use of blogs in education will be the

Manuscript received April 9, 2015; revised June 19, 2015.

J. C. Kush is with the Duquesne University, Pittsburgh, PA 15282 USA (e-mail: kush@duq.edu)

N. R. Miller is with the Katy Independent School District, Katy, TX 77494 USA (e-mail: nrothmiller3@gmail.com). primary focus.

Blogging creates a community of learners from the beginning through active learning, which enhances the overall learning process. Additionally, blogs appear to have a distinct advantage over in-class discussions as blogging encourages and nurtures meditative and reflective practices. Oftentimes, classroom discussions may be too rapid-paced for all students to feel comfortable enough to participate as they form uncertain ideas and gain confidence in their own understanding or mastery of a topic. Blogs on the other hand, offer time for students to focus and space for students to explore new ideas, research, process, and respond to topics that are being discussed in a given forum. With blogs, students have the opportunity to reflect before becoming involved, which is something that does not always occur in traditional classroom settings [7], [8]. Blogging can also support collaborative learning by enhancing learning performance in both individual knowledge development and group knowledge sharing.

Of greater importance, blogs have gained popularity and credibility as a means for finding quality and relevant materials quickly for both instructors and students alike, though it remains to be seen just how trustworthy or useful available information really is. Regardless, blogs can make it easier to find links to supplemental and enrichment reading materials on any given subject, in additional to personal ideas and opinions, which can be tremendously beneficial in the any classroom. All in all, instructors can use blogs as a source of information on pertinent topics and as a means for creating a community of learners through virtual classroom interaction, thus nurturing a solid learner-centered environment.

Furthermore, both students and instructors can be connected at any time, which helps create the society of learners that is so sought after in today's educational and business worlds. In fact, blogs can open doors to the entire world; thus creating a more global awareness than traditional classrooms can offer. Through blogging, instructors can encourage learning above and beyond pre-set standards and objectives and create assignments that fully take advantage of peer editing processes that exceed the time and physical constraints of traditional classroom environments. As a result, students will become more aware of their audience and their own written voice. Receiving almost immediate feedback from their peers on their own writing promptly identifies problem areas regarding cohesion and clarity in writing style. This allows the writer to become more adept at determining what revisions might be needed in order to meet the needs of their specific audience and should serve to stimulate interaction and inquiry.

Having an instant audience and a place to broadly publish are also important aspects of how blogging can benefit 
students in learning to write. Until now, it was commonplace for a student to write a paper, and the only other person to ever see that paper was an instructor and perhaps a peer editor or two. With blogging, however, it is possible for dozens of peers and instructors to review a piece before it is ever formally assessed. Knowing that other eyes can scrutinize, and even better, offer advice, places students in a more authentic learning environment than traditional writing instruction could ever hope to do. Ultimately, blogs should encourage students to produce more publishable pieces each and every time they write.

Being able to see how one's peers are progressing forms a connection among students. For example, recognizing that other people may be having the same difficulties allows students to know that they are not alone in their struggle. Acknowledging that other people are there to assist in the learning process creates something of a safety net that encourages writers to think outside the box and facilitates risk-taking in their own writing. Moreover, if one student in the blogging group is struggling with a particular concept, their peers may be able to direct their thinking in a new, easier to understand direction. In essence, it is as if each student has a variety of tutors with a plethora of different approaches to understanding any one concept.

Students can share their learning experiences and express their thoughts to the instructor and their peers through course blogs and can post examples related to assignments as well as discuss reflections on course materials. Ultimately, using blogs in the writing classroom encourages active learning. Students, instructors, and even outside experts (if invited to participate) equally have the opportunity to engage in dialogue regarding all aspects of the writing process including audience awareness, thesis creation, organization and structure, development of support through reasons and details, and the maturation of style. This type of active learning strengthens peer response skills and builds confidence.

\section{PURPOSE OF THE STUDY}

The primary goal of this study was to examine the efficacy of blogging on weekly journaling assignments as students progressed through a standard ninth grade writing unit. The objective of this study was to compare the overall progression of writing proficiency and overall enjoyment experienced by three distinct groups of high school students: a) those who progressed through the standard ninth grade writing unit and practiced writing through handwritten entries in traditional blue books (please note that this activity is commonly referred to as journaling in the literature classroom), b) those who progressed through the same ninth grade writing unit and practiced writing with word processing applications, and finally, c) those who progressed through the writing unit and practiced writing through a class invite-only blog. Ultimately, this study determined if there were differences among the groups in the progression of their writing proficiency and in their overall enjoyment of the instructional practice.

\section{METHOD}

Participants consisted of three independent groups of ninth grade students. A total of 104 students were formally assessed on their journaling activities and the overall progression of their writing proficiency in addition to their overall enjoyment of the instructional practice. Group 1 represented the control group and was taught the writing unit using traditional methods including a journaling component, which was carried out in standard composition notebooks. Group 2 reflected the first treatment group. They too were taught the writing unit through traditional methods, but their journaling component was carried out through a word processing application. Finally, Group 3 represented the second treatment group. This group was taught the same writing unit through the same traditional methods, but their journaling component was conducted through an invite-only class blog.

All three groups of participants intentionally had the same classroom instructor. The decision was made in an effort to control the material and pace of instruction that was delivered to all subjects. In order to guarantee that all three groups received equal and fair instruction, however, the participants were dispersed throughout the day in five sections of the English 9-Level II (students of average ability level) course. Therefore, each of the five classes taught by the instructor contained a sampling of participants from each of the three different journaling groups thereby eliminating any favoritism toward a particular journaling prompt or medium. More importantly, the instructor did not function as an evaluator regarding any data related to this study. Independent observers were also invited to intermittently monitor the classes throughout the study in an effort to ensure that the instructor/ researcher taught not only the same material but also with the same effectiveness and enthusiasm so as to further avoid any potential biases in relation to the study.

\section{A. Instruments}

Holistic teacher-created assessments were administered throughout the course of study and assessed such criteria as whether students were able to integrate and synthesize the concepts and principles discussed in class into their own writing, if they were focused, if they showed critical thinking skills, if they were able to smoothly integrate outside resources, if they included relevant personal experiences, and if they were able do all of this in a timely manner. All participating students were tested on their overall writing proficiency and skill at the beginning and then again at the conclusion of the unit of study.

The first test (pre-test) was administered to all participants before the start of the writing unit. This test provided baseline information as to the overall writing skill level of each of the three test groups at the start of the unit of study. This test, as with the final writing unit examination, consisted of timely ninth grade Pennsylvania System of School Assessment (PSSA) writing prompts. Upon conclusion of the writing unit, all students were given a post-test that was assessed in the same manner as the pre-test. A team of three pre-selected assessors from within the participating school's English department assessed all writing samples. All of the assessors were familiar with the standard PSSA grading rubric, and all had years of experience using the rubrics to grade student writing. The rubric measures elements such as focus, organization, content, usage, and style. 
Additionally, all participants in each of the three groups were asked to complete a teacher-created survey that examined enjoyment levels experienced throughout the writing unit. This survey concentrated on the journaling activity and examined participant enjoyment of the activity and their belief that the activity was academically beneficial.

\section{B. Participants}

This study was conducted in a moderately sized and predominately middle-class suburban public school district located ten miles south of Pittsburgh, PA. The district consists of five elementary schools, two middle schools, and one senior high school. The high school is made up of grades 9-12 and accommodates approximately 1,800 students annually, a majority of who are Caucasian. The sample size included 34-35 students per experimental group. The sample size of 104 students satisfied the ANOVA power requirements necessary to detect a small to medium effect size. In order to correct for multiple comparisons, the study utilized at an alpha level of .001 .

\section{Procedure}

Throughout this study, students in Groups 2 and 3 used computer labs containing PC computers with high-speed Internet access. A security system (St. Bernard ${ }^{\mathrm{TM}}$ ) was used on all networked computers in the district, and all accounts were password protected.

eBloggy was the blogging software of choice for this study for several reasons. First, eBloggy had previously been successfully implemented into other classrooms within the district, so compatibility and ease of use had already been determined. Additionally, eBloggy was free, yet it still provided a variety of useful features including blog statistic tracking, pre-existing templates that could be customized, point-and-click link management, and, most importantly for the purpose of this study, group blogs. Finally, eBloggy allowed the instructor to keep the information that was posted to the class blog private from the general public. In fact, this information was available for viewing by only those who had been invited to join the class blog. Ordinary Internet users were not able to view their content. To ensure anonymity, students were instructed to establish their accounts during class time with guidance and were instructed to not include any personally sensitive material including last name, address or location, phone number, age, or photographs of any kind.

Finally, students in all three groups were provided the opportunity to engage in peer-review practices. On designated peer-review days, every student exchanged one of his or her essays with another student. Students in the handwriting and word processing groups had the opportunity to view hard copies of the other students' work only on the peer-review days. Otherwise, the only person who saw the hand writers' and the word processors' work was the individual who assessed it. In contrast, students in the blogging group knew that as soon as they posted their essays, anyone who was participating in the invite-only class blog would be able to view their work; hence, they had an instant and ever-present audience to consider every time they logged onto the blog.

\section{Evaluation}

All students who participated in the study were instructed in the journaling process and were given class time to do so. Students in all three groups were also encouraged to journal outside of class and could do so either in school or at home. In general, all groups journaled during provided class time using the assigned journaling method. Specifically, students in the blogging group were asked to respond to a teacher-selected writing prompt by posting their responses to the class blog by the end of the given class period. Students who journaled by handwriting their responses in blue composition books and students who journaled by word processing their responses were also asked to respond to the same teacher-selected writing prompt on the same day and within the same time constraints.

A focused writing prompt was provided both in class and posted online by the instructor at the beginning of each weekly journaling session. Students were asked to respond to this writing prompt as they would any formal writing assessment. Supplementary assignments and writing practice were completed by each of the three journaling groups throughout the writing unit in addition to the weekly journaling sessions conducted for the purposes of this study.

\section{RESUlTS}

Out of a total of 129 possible participants, twenty-three immediately opted out of participating in this research study. Two individuals who originally agreed to participate had to be dropped from the study due to being transferred to an alternative program. All students who remained in any of the five sections of English 9 - Level II were exposed to the same material at the same pace. Only those students and their parents/ guardians who gave consent had their data included in the study. Data collection resulted in a total sample of 104 participants including 35 participants in Group 1 (the handwriting group), 34 participants in Group 2 (the word processing group), and 35 participants in Group 3 (the blogging group).

TABLE I: DESCRIPTIVE STATISTICS: PARTICIPANTS IN THE HANDWRITING

\begin{tabular}{llllll}
\multicolumn{7}{c}{ TREATMENT GROUP } \\
\hline VARIABLE & $N$ & MINIMUM & MAXIMUM & MEAN & SD \\
\hline PRETEST & 35 & 2 & 4 & 2.91 & .78 \\
POSTTEST & 35 & 1 & 4 & 2.94 & .80 \\
DIFFERENCE & 35 & -2 & 2 & .03 & .82 \\
QUESTION 1 & 35 & 1 & 5 & 3.46 & 1.60 \\
QUESTION 2 & 35 & 0 & 1 & .86 & .36 \\
\hline
\end{tabular}

TABLE II: DESCRIPTIVE STATISTICS: PARTICIPANTS IN THE WORD PROCESSING TREATMENT GROUP

\begin{tabular}{llllll}
\hline VARIABLE & $N$ & MINIMUM & MAXIMUM & MEAN & SD \\
\hline PRETEST & 34 & 1 & 4 & 2.65 & .98 \\
POSTTEST & 34 & 1 & 4 & 2.88 & .77 \\
DIFFERENCE & 34 & -2 & 2 & .24 & 1.08 \\
QUESTION 1 & 34 & 1 & 5 & 3.94 & 1.01 \\
QUESTION 2 & 34 & 0 & 1 & .91 & .29 \\
\hline
\end{tabular}

Descriptive statistics for all three journaling groups are presented in Table I - Table III. These descriptive statistics indicate that all three journaling groups' writing scores improved slightly over the course of the study. The results also revealed that there were minimal differences in the level of enjoyment of the journaling activity among the three journaling groups. For all Tables, Question 1 asked students to rate their overall enjoyment of the journaling activity and 
Question 2 asked them if they believed that their overall writing proficiency and/or skill improved because of journaling.

TABLE III: DESCRIPTIVE STATISTICS: PARTICIPANTS IN THE BLOGGING TREATMENT GROUP

\begin{tabular}{llllll}
\hline VARIABLE & $N$ & MINIMUM & MAXIMUM & MEAN & SD \\
\hline PRETEST & 35 & 1 & 3 & 2.03 & .57 \\
POSTTEST & 35 & 2 & 4 & 3.28 & .60 \\
DIFFERENCE & 35 & 0 & 3 & 1.20 & .76 \\
QUESTION 1 & 35 & 1 & 5 & 3.23 & 1.69 \\
QUESTION 2 & 35 & 0 & 1 & .91 & .28 \\
\hline
\end{tabular}

It can be seen that at the start of the study the handwriting group had the highest average score, while the word processing group lagged slightly behind. Additionally, while the handwriting group started out with higher achievement, they ultimately made only minor gains in writing performance over the course of the study. In contrast, while both the handwriting group and the word processing group made some progress from their pre- to their post-test scores, the blogging group did significantly better than both groups when compared to the pre-test scores. Further, the blogging group ultimately exceeded the mean scores of both the handwriting group and the word processing group on the post-test despite the fact that they had the lowest mean pre-test scores out of all three groups.

\section{A. Group Comparisons}

The first analysis of variance revealed a significant difference in writing growth among the three groups, $(F$ $(2,101)=17.09, p=.0001)$, with a significant increase in performance from the pre-test to the post-test scores of participants in the blogging group when compared with participants in both the handwriting and the word processing groups. Although, the word processing group began with high achievement, they made little gain in writing performance over the course of the study. Most importantly, while the blogging group did much worse on the pre-test as compared to either of the other two groups, they demonstrated the largest gain in writing performance over the course of the study.

The second analysis of variance revealed no significant difference among the groups' ratings of their level of enjoyment of the journaling activity in which they took part, $(F(2,101)=1.07, p=.35)$. Most students felt that participating in the journaling activity, regardless of which method they were asked to employ, was simply "average". Participants in the blogging group indicated that they thought their journaling experience was slightly better than average registering a mean satisfaction score of 3.23. However, the blogging groups' satisfaction score was slightly below the handwriting groups' mean score of 3.46.

The final analysis of variance also demonstrated no significant differences among the three groups, $(F(2,101)$ $=.38, p=.69$ ) in their perception of whether they believed the journaling activity improved their overall writing proficiency. In fact, a majority of participants (90 out of 104), regardless of which journaling method they employed, suggested that they believed that journaling did improve their writing proficiency throughout the eleven-week study period. However, no one group felt more strongly that their specific journaling medium improved their overall writing proficiency than either of the other groups.

\section{CONCLUSION}

It is widely accepted that writing is a staple in the thinking and learning process, yet little has changed in its teaching throughout the history of education. The technological revolution has changed the drafting and revision process, but little else ... until now. New technologies continue to emerge, and if used properly, can greatly benefit the teaching and learning of the writing process. One such example is the blog. Blogs are clearly intrinsically writing based; and therefore, they appear to be a perfect complement to traditional writing instruction. However, very little empirical data is currently available examining the overall impact that blogging might have in education, and more specifically, on student writing.

Therefore, the purpose of this study was to determine whether any particular method of journaling (handwriting, word processing, or blogging) would result in the increased writing proficiency in typical, high school-aged students over time. Regardless of the outcome, the results of such a study could potentially demystify how students write, and consequently, would add to the very narrow background knowledge in this field of study. That said, it was extremely important that only the journaling methods and their impacts were targeted. This meant that other variables that typically contribute to performance fluctuations such as instructor style, pace, attitude, and evaluation had to be strictly controlled.

It was assumed that varying instructor style and pace could, and most likely would, affect how well students performed throughout the study. As a result of this assumption, only students enrolled in the five sections of English 9 - Level II taught by the researcher were eligible to participate in the research study. Thus, every student in the earmarked classes received the same instruction on the same day in the same delivery style regardless of participation status or which journaling group they were randomly assigned to. Consequently, no one student or group of students would have the benefit of having covered more writing-based instruction than another student or group of students; hence ensuring that no one had an unfair advantage.

This study is among the first of its kind in that very little research is available on the use, and more importantly, on the impact of blogging in the classroom setting. In fact, before this study, no research existed to empirically prove that blogging could be the catalyst for improved student writing performance; and therefore, this study is of considerable value to not only those instructors who teach writing, but also to all instructors who have students write. As a result, this study can serve as a springboard for other researchers to move beyond simply whether blogs should be implemented into classrooms at all, to investigating which classrooms and age brackets would most benefit from blogs, and to discovering the best methods for implementation overall.

Furthermore, this study supports the idea that blogging is continuingly becoming more mainstream in today's society, and schools must take steps to expose students to the blogging world in order for them to be more successful after graduation. There is evidence that blogging is becoming more of a web-presence of choice in today's world [9]. There is also 
abundant research demonstrating that schools and businesses around the world are beginning to incorporate blogging in an effort to stay more current and to better market themselves. Blogs continue to gain in popularity with the estimate that in 2005, at least eight million Americans alone had created blogs or web-based journals [10]. And yet, the educational benefits of blogs have been widely uninvestigated and under reported. Now, however, there is data to support the educational benefits of blogging in writing classrooms.

More importantly, educators have continuously debated whether or not communication technologies such as blogging, chatting, and texting actually degrade the quality of writing in today's youth. This study proves that blogging is beneficial, not harmful, to students' writing skills, and therefore, should bring about a change in attitude concerning the implementation of blogs into the classroom setting among school stakeholders. This study supports older theories such as Vygotsky's [11] as it points to the importance of social interaction in educational experiences in order to construct knowledge and make meaning. Again, it appears that blogging does just that. Blogs provide a means for empowering writers, and they give students the ability and the resources to become published authors from the comfort of their own classrooms [12]. Clearly, this study is consistent with findings that blogging affords students the opportunity for authentic learning and the freedom to develop and publish their own ideas to a real audience; thus producing more solid writers over time [13].

This study demonstrates that school stakeholders should re-evaluate their stance on introducing blogging into high school settings. Many administrators and parents reject the idea of allowing students to engage in online discussions due to an inherent fear of opening children up to potential predators or the harsh realities of life. And while there are certainly risks to be considered including exposing impressionable students to the negatives of the online environment and the sometimes frustrating side-effects of technology enhanced learning, the overall benefits of implementing a technology such as blogging into high school writing classrooms is now unmistakable. Perhaps the results of this study will bring about a shift of thinking among stakeholders so that they can begin to dedicate more time and energy to effectively integrating web-based instruction so that it is not only safer but also more productive rather than using their time and energy devising ways to shield students from participating in such endeavors.

Ultimately, if students are sheltered from becoming actively engaged in the online environment, academic institutions run the risk of graduating students who are uncomfortable both with and in the changing world around them. In short, there is great demand for the educational world to keep pace with the changing society in which it functions, and this study is a primary step in the right direction.

\section{REFERENCES}

[1] D. Jonassen, "Designing constructivist learning environments," in Instructional-Design Theories and Models: A New Paradigm of
Instructional Theory, C. M. Reigeluth Ed., Mahwah, NJ: Lawrence Erlbaum Associates, 1999, pp. 215-239.

[2] T. M. Harrison and B. Barthel, "Wielding new media in Web 2.0: Exploring the history of engagement with the collaborative construction of media products," New Media \& Society, vol. 11, no. 1-2, pp. 155-178, 2009.

[3] J. Davies and G. Merchant, "Negotiating the blogosphere: Educational possibilities," Digital Literacies, UKLA/Sage, 2009, pp. 81-94.

[4] J. Davies and G. Merchant, "Looking from the inside out: Academic blogging as new literacy," A New Literacies Sampler, New York: Peter Lang, 2007, pp. 167-98.

[5] J. Gee, Situated Language and Learning: A Critique of Traditional Schooling, London: Routledge, 2004.

[6] M. Knobel and C. Lankshear, A New Literacies Sampler, New York: Peter Lang, 2007.

[7] H. Y. Hsu and S. H. Wang, "The impact of using blogs on college students' reading comprehension and learning motivation," Literacy Research and Instruction, vol. 50, pp. 68-88, 2010.

[8] S. H. Yang, "Using blogs to enhance critical reflection and community of practice," Educational Technology \& Society, vol. 12, no.2, pp. 11-21, 2009.

[9] E. Brownstein and R. Klein, “An educator's guide to blogs," presented at the 2005 NECC Conference, 2005.

[10] P. D. Long. (2002). Blogs: A disruptive technology coming of age? [Online]. www.campus-technology.com/print/asp? $\mathrm{ID}=6774$

[11] L. S. Vygotsky, Mind and Society: The Development of Higher Mental Processes, Cambridge: Harvard University Press, 1978.

[12] T. Martindale and D. Wiley, "Using weblogs in scholarship and teaching," TechTrends, vol. 49, no. 2, pp. 55-61, 2005.

[13] R. E. Ferdig and K. D. Trammell, "Content delivery in the 'blogosphere," T.H.E. Online Journal, 2004.

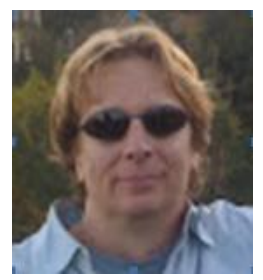

Joseph C. Kush was born in Topeka, KS, in the United States, and received his Ph.D. in 1985 from Arizona State University, located in Tempe AZ, in educational psychology.

$\mathrm{He}$ is currently is a professor in education at Duquesne University in Pittsburgh, PA. He is also the director of the doctoral program in educational leadership and instructional technology. He is also a visiting professor, at the Shaanxi Institute of International Trade and Commerce. Xi'an, China. His research interests include issues related to assessment and test fairness, using technology to enhance learning, and music technology. He has published numerous peer reviewed journal articles. And he has written book chapters, and is co-editor for the book Technology Implementation and Teacher Education: Reflective Models. As an accomplished guitarist who uses McIntosh computers exclusively he has also co-authored a chapter on music technology.

Professor Kush is a member of the Association for the Advancement of Computing in Education and has received the Distinguished Reviewer Award from the Buros Mental Measurement Yearbook.

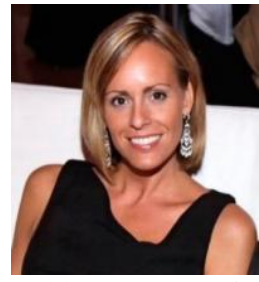

Nicole Roth Miller obtained both an M.S.Ed. and an Ed.D. in instructional technology from Duquesne University in Pittsburgh, PA in 2003 and 2007 respectively, and a B.S.Ed. in secondary English education in 1998 from Clarion University, Clarion, PA. She began her career in education at Bethel Park High School in Pennsylvania where she taught English, coached swimming, and oversaw the Writing Center. After leaving Bethel Park, she worked as the English language arts instructional coach for Mayde Creek High School in Katy, TX Currently, she serves as the secondary instructional coach facilitator for the Katy Independent School District. In this role, she is dedicated to collaborating with junior high and high school instructional coaches to incorporate best practices in teaching, interpret student data, and coordinate curriculum in an effort to improve student learning. Dr. Roth Miller has attended and presented at various academic conferences in the field of English language arts and educational technology. 